\section{Tricyclic Antidepressants}

SIR,-I am worried by one sentence in the article on tricyclic antidepressants (13 April, p. 102): "Jaundice, which is very uncommon, is of the cholestatic type similar to that found in chlorpromazine." This is misleading.

Jaundice is one of the more frequent sideeffects reported from imipramine and imitriptyline, the most widely used members of the group. Its incidence is probably related to the amount of drug prescribed, and is only newer compounds. I doubt, too, if the jaundice is always of the chlorpromazine type; this implies a cholestatic reaction which is usually benign. Some patients almost certainly have a far more serious hepatic reaction, and death can result from liver-cell failure.-I am, etc.,

\section{Dudley Road Hospital}

A. Paton. likely to be "very uncommon" with the

\section{Blood Pressure in Sleep}

SIR,-I have been interested to read the article by Dr. Ian Oswald and others (30 March, p. 796), and in particular one comment that is made, that nitrazepam suppresses paradoxical sleep."

My own interest is in the effect of sleep on the blood pressure. By continuous recording of the blood pressure I have noted the gradual lowering and the periods of recovery of the blood pressure to near normal in natural sleep. In patients sedated with nitrazepam there has been little or no effect on the blond pressure-that is to say, there is just as high an incidence of blood pressure recovery periods as there is in unsedated sleep. I have not found this in patients sedated with barbiturates or with methaqualone-in these there is lowering of the blood pressure with few recovery periods. MacWilliam ${ }^{2}$ described two different conditions of the state of sleep: " undisturbed or sound sleep" with a lowering of the blood pressure, heart, and respiratory rate, and " disturbed sleep," modified by reflex excitations, dreaming, nightmares, sometimes with extensive rises in blood pressure, increases in heart rate, and various reflex effects. I have assumed that his "disturbed sleep" was the same state later described by Jouvet ${ }^{3}$ as " paradoxical sleep."

If nitrazepam suppresses paradoxical sleep I would have expected few blood pressure recovery periods, but this is not the case. Would Dr. Oswald say I am wrong in assuming that MacWilliam's " disturbed sleep" is similar to Jouvet's "paradoxical sleep" and that the recovery periods of the blood pressure coincide with the rapid eye movements of paradoxical sleep ?-I am, etc., considerable experience more widely known and that in consequence inductively coupled pacing may receive the more extensive trial it deserves.-We are, etc.,

centre. All patients living at a distance either consult their own doctor if in difficulties or return faulty components to Lucas themselves. In a region in which patients may live more than 80 miles from the special centre this is important. Other advantages of the induction unit are the controllable rate which is used by our more physiologically minded patients, and the ease with which it can be stopped. Sinus rhythm has returned in two patients while being paced by the induction unit, and a possibly fatal competition between the natural and implanted pacing units has been avoided by removing the artificial stimulus.

In the present state of electronic miniature stimulators (Dr. Sowton's survey revealed $57 \%$ failed) it seems rational to put the electronics outside, where the informed patient can get at them at once if something goes wrong.-I am, etc., Sheffield.

DAVID VÉREL.

REPERENCE

1 Abrams, L. D. Hudson, W. A., and Lightwood, R., Lancet, 1960, 1, 1372

SIR,-The recent survey on artificial cardiac pacemakers (6 April, p. 11) highlights the fallibility of totally implanted pulse generators, and affords support for the use of the Lucas inductively coupled system.

We use this inexpensive system, with an endocardial electrode, and find it very suitable for permanent pacing in an area where patients live many miles from skilled help. The external pulse generator is simple and uses $\mathrm{U} 2$ cells, which are widely available and easily replaced. The patient has a spare generator and primary coil as an immediate remedy should faults develop in the external

\section{East Anglian Regional Cardiac Unit Papworth Hospital \\ J. H. N. BetT \\ D. W. Evans \\ REFERENCE} Abrams, L. D., Hudson, W. A., and Lightwood,
R., Lancet, 1960, 1, 1372 .

SIR,-May I correct the reference to corticosteroid therapy made by Drs. B. W. Lassers and D. G. Julian (20 April, p. 142)? The article they quote ${ }^{1}$ reported the treatment of cases of heart block complicating acute myocardial infarction with oral steroid therapy. The shortening of the $P-R$ interval by corticosteroid therapy, to which they refer, was reported by myself in a later article, ${ }^{2}$ in which I also reported the advantages of a high-dosage, parenteral, hydrocortisone regimen in the treatment of " acute" heart block over the earlier series. In a group of 17 cases of complete heart block complicating acute myocardial infarction treated with parenteral steroids two died within three hours of onset, but the remaining 15 were restored to sinus rhythm within 24 hours. There were two late deaths in this group (pulmonary embolism at 10 days and fresh infarct at five weeks) but no recurrence of heart block, and 13 were discharged home. Continuing experience ha; not caused me to change this regimen.-I am, etc.,

Royal Alexandra Infirmary, J. L. C. DALI. Paisley.

REFERENCES

2 Dall, J. L. C., and Buchanan, J., Lancet, 1962, 2 Dali, J. L. C., Brit. Heart F., 1964, 26, 537.

\section{A. W. RAFFAN}

Royal Infirmary

ReFERENCES

1 Oswald, I., and Priest, R. G., Brit. med. F., 1965, 2,1093

( MacWilliam, J. A., Brit. med. F., 1923, 2, 1196. Jouvet, M.. Report on Current Research presented at Annual Meeting of Association
Physiological Study of Sleep, 1965 .

\section{Post-infarction Electrocardiogram}

SIR,-Solomon and Shapiro' have described seven patients who showed a temporary improvement or reversion to normal in their electrocardiograms after myocardial infarction. I wish to report a further case.

The patient was a 54-year-old male who had been healthy in the past. Three days before admission he had suffered a minor incident of chest pain which lasted two hours. On the day of admission an urgent request for a visit was received at 6 a.m. He had awoken with severe pain across the lower chest, which radiated down the inside of the right arm. He was found to be shocked and sweating. The diagnosis of myocardial infarction was subsequently supported by both clinical and laboratory evidence.

The first electrocardiogram, done three hours after the onset of pain, showed typical injury changes with elevation of the ST segments in standard leads II, III, and AVF. A second tracing taken six hours after the incident was, by the majority opinion of a number of cardiologists, within normal limits. After 12 hours the usual progression had been resumed with inversion of the 